\title{
Coulisses
}

Revue de théâtre

12 | Printemps 1995

Varia

\section{Le Centre Jacques-Petit de Besançon}

Jacques Houriez

\section{OpenEdition}

Journals

Édition électronique

URL : http://journals.openedition.org/coulisses/3254

DOI : $10.4000 /$ coulisses.3254

ISSN : 2546-9460

\section{Éditeur}

Presses universitaires de Franche-Comté

\section{Édition imprimée}

Date de publication : 1 mai 1995

Pagination : 6

ISSN : 1150-594X

\section{Référence électronique}

Jacques Houriez, «Le Centre Jacques-Petit de Besançon », Coulisses [En ligne], 12 | Printemps 1995,

mis en ligne le 15 mars 2019, consulté le 21 octobre 2019. URL : http://journals.openedition.org/ coulisses/3254; DOI : 10.4000/coulisses.3254

Ce document a été généré automatiquement le 21 octobre 2019

Coulisses 


\title{
Le Centre Jacques-Petit de Besançon
}

\author{
Jacques Houriez
}

1 Le Centre Jacques-Petit, dont le siège se trouve à la Faculté des Lettres de Besançon, regroupe une quinzaine de chercheurs universitaires, parmi lesquels dix extérieurs à la Franche- Comté.

Sa mission est double. D'une part, il gère les fonds de manuscrits qui lui ont été confiés par les familles Claudel et Bloy ainsi que par l'écrivain bisontin Claude Louis-Combet. C'est à ce titre essentiellement qu'il a reçu le label CNRS. Il est, de l'autre, un centre de recherches sur la littérature française des XIX ${ }^{\text {ème }}$ et XX ${ }^{\text {ème }}$ siècles.

2 Il est surtout connu comme un centre claudélien, et, en effet, son fonds Claudel est le plus complet et le plus important.

Il comprend tous les microfilms des manuscrits autrefois détenus par les Archives Paul Claudel et cédés par la famille à la Bibliothèque Nationale. S'y ajoutent des correspondances personnelles et des documents dont certains particuliers ont permis le microfilme, ou dont le centre a acheté les manuscrits, les correspondances diplomatiques et consulaires des Archives ministérielles des Affaires Étrangères de Paris et Nantes, des documents communiqués par les Archives diplomatiques de Tokyo. Cet ensemble fait que, pratiquement, toute étude claudélienne, en France ou à l'étranger, se fait par son entremise, soit par l'envoi de photocopies de documents, soit par l'étude sur place.

Il a permis, en outre, l'édition à la Bibliothèque de l'Âge d'Homme de plusieurs correspondances familiales, trois volumes d'œuvres complètes faisant suite aux vingtneuf publiés chez Gallimard, et un volume des agendas de Chine, une correspondance consulaire, un volume de correspondances diplomatiques d'Amérique, après un Claudel et l'Amérique et avant un Claudel et le Japon chez Gallimard. Deux volumes de correspondances littéraires sont sur le point d'être livrés à l'éditeur, ainsi que deux autres d'œuvres complètes.

Les correspondances diplomatiques d'Alexis Léger - Saint-John Perse et de Paul Morand sont en préparation.

3 Pour Léon Bloy, les éditions critiques du Désespéré et de La Femme pauvre sont en cours. 
4 Par ailleurs, dans le cadre des études sur les XIX ${ }^{\text {ème }}$ et $X^{\text {ème }}$ siècles, soixante-neuf volumes ont été publiés à ce jour, deux sont en cours de publication, quatre le seront prochainement. Les colloques que le centre organise: "Christophe Colomb et la découverte de l'Amérique ", Besançon, mai 92, "État présent des recherches claudéliennes », Brangues, octobre 93, "Écritures claudéliennes », Besançon, mai 94, «Henri Michaux, l'Encre ou la Plume», Besançon, novembre 95, ou auxquels il participe, «La révolte dans le théâtre espagnol et européen, de 1890 à 1913 », Besançon, septembre 95, donnent également lieu à des publications.

Encore ne s'agit-il là que des activités proprement bisontines, car des équipes de Grenoble et Montpellier se sont intégrées à notre centre, et leurs activités portent essentiellement sur la représentation des idéologies, les formes de la poésie religieuse et les études bloyennes.

La publication dans Coulisses des quatre conférences données à l'occasion des représentations de Partage de Midi par le metteur en scène Alain Ollivier montre, enfin, son implication dans la vie culturelle bisontine. 